\title{
Cellular concrete waste as an economical alternative to traditional supplementary cementitious materials
}

\author{
Zoltán Gyurkó $^{1} \cdot$ Anna Szijártó $^{1} \cdot$ Rita Nemes ${ }^{1}$ \\ Received: 1 October 2018/Accepted: 26 April 2019/Published online: 13 May 2019 \\ (C) The Author(s) 2019
}

\begin{abstract}
Traditional supplementary cementitious materials (SCMs), like metakaolin or microsilica, highly improve various properties of concrete, making it more resistant against the effects of the environment. However, the cost of concrete is highly influenced by the applied amount of SCMs. Cellular concrete powder (CCP) is a by-product, produced by the cutting and curving process of cellular concrete blocks, which has the possibility to be used for similar purposes as SCMs. The present paper introduces the results of the laboratory experiments, conducted by the authors, and their analysis. The experiments were designed to investigate the effects of $\mathrm{CCP}$ on mortars, normal and high-strength concretes in terms of strength and durability. To get a deeper understanding of the processes taking place in a mortar or concrete containing CCP, thermogravimetric analysis was performed as well. CCP was applied in the mixes in different amount, and the performance of CCP was compared to SCMs. CCP was found to be a feasible alternative to SCMs in case of normal-strength concrete, while in case of high-strength concrete it did not improve the strength of the reference concrete. It could be traced back to the sulfate swelling of CCP particles. In optimal dosage, CCP was found to be preferable to metakaolin (MK) for durability characteristics. The combined usage of CCP and MK was investigated as well, but it did not result a concrete with better performance than the reference mix.
\end{abstract}

Keywords Cellular concrete powder · Waste material · Freeze-thaw resistance · Outdoor structural concrete · Supplementary cementitious materials $\cdot$ Metakaolin

\section{Introduction}

Many researches on concrete are aiming to create more advantageous concrete from strength and durability standpoint with the application of innovative admixtures and supplementary cementitious materials (SCMs) [1]. SCMs are highly advantageous, because besides their positive effects on strength and durability, they have environmental benefits, like the reduction in carbon dioxide emission and decreasing the porosity of normal-strength concrete [2-6]. The strict European air pollution regulations have produced many industrial by-products that can be used as supplementary cementitious materials, like metakaolin (MK) or

Zoltán Gyurkó

gyurko.zoltan@epito.bme.hu

1 Department of Construction Materials and Technologies, Budapest University of Technology and Economics, Müegyetem rkp. 3, Budapest 1111, Hungary silica fume. SCMs are applied to increase strength or enhance durability or to simply decrease cement content (as the most expensive component of concrete). However, nowadays the cost of typical SCMs (metakaolin, silica fume) is increasing due to the high demand. Thus, researchers should look for other types of low-cost materials, which can have similar positive effects as SCMs.

Various waste materials can be used as SCMs as it was showed [7, 8]. Mechanical behavior of different waste materials was investigated by several researchers [9-12]. Ceramic waste was used as SCM in the study of Bignozzi and Saccani [13], and it was proven to be a valid alternative to cement. In the research of Puertas [14], ceramic wastes (fired red or white wall tiles) were applied in cement clinker production. The research showed that the particle size of the applied waste material was lower than $90 \mu \mathrm{m}$, which resulted in a higher reactivity of this type of cement. The effect of particle size (surface area) of waste materials used as SCMs was investigated, and it was found that the 
higher surface area (so smaller particle size) resulted higher compressive strength and strength activity index [15]. The relationship of specific area and compressive strength was shown to be linear.

Recycled glass with proper chemical composition and average fineness could be used as SCM as well [16]. Pozzolanic behavior was determined by using indirect (compressive strength test) and direct (thermogravimetric analysis) methods [17]. By the usage of thermogravimetric analysis and calorimetry, the hardening process and the mechanism of hydration in cementitious systems can be investigated [18-21]. Based on that, it can be investigated whether a material is suitable for potential SCM or not.

In the present study, the waste of production and installation of cellular (aerated) concrete blocks are investigated. The blocks are made from lightweight aerated concrete, which besides its structural role provides heat insulation as well $[22,23]$. During the production and the cutting of the blocks, huge amount of waste material in form of powder is produced. The cellular concrete powder (CCP) could be easily collected and later used as concrete component. An advantage of CCP is that it is in the form of fine powder, as the result of the cutting process, thus no further preparation is needed before it is mixed to the other components of concrete. The main reaction product in cellular concrete belongs to the tobermorite group of calcium silicate hydrates $(\mathrm{C}-\mathrm{S}-\mathrm{H})$ [24]. These products have very high specific surface area and are stable, which indicates that they may be used as SCM. There were already attempts to reuse the waste of cellular concrete as aggregate at the department of the authors [25, 26]. The results showed a slight decrease in performance, when the cellular concrete waste was added to the concrete mix as coarse aggregate. In our research, CCP is applied in the form of fine powder.

\section{Research objectives}

The objective of this research is to investigate the effect of $\mathrm{CCP}$ on normal-strength concrete (NSC), by using different concrete mixes. It is aimed to find a roughly optimal quantity of CCP in concrete and compare it to SCMs in strength and durability point of view. The dosage of SCMs or CCP could be very important, because above a given amount, SCMs reduce the performance of both strength and durability parameters [27]. In Borosnyói's study [27], a research program is introduced, which was performed at the Department of Construction Materials and Technologies, at BUTE. In that study, SCMs applied in concrete with different dosages were investigated at various ages. High-strength concrete (HSC) mix (C60/75) was used that contained maximum $17 \%$ (compared to the mass of cement) SCM. The applied SCMs were silica fume, metakaolin and the mix of them. The major outcomes were the following:

- the optimal amount of SCM is close to $10 \%$, which was also found in other studies [28],

- the strength increase, caused by the SCMs, is the highest at 28 days of age. After that, in all cases, a proportionally smaller strength increase was measured.

- The mixture, when the two SCMs were mixed, performed better than the reference mixture, but not better than the SCMs applied singly.

\section{Research plan}

The research plan of present study to achieve the stated objectives was the following:

1. Firstly, the effect of CCP was investigated on cement mortars containing different amount of $\mathrm{CCP}$ or MK. Here, the aim was to see clearly the effect of CCP without any other possible disturbances.

2. In the next step, a given percentage of cement is substituted by CCP in normal-strength concrete. The mixes with different amount of CCP are compared to a mix containing MK and another containing the mixture of CCP and MK.

3. Then, a high-strength concrete mix (same as presented in the study of Borosnyói [27]) is used and CCP is mixed to the concrete mix, by substituting a given amount of cement. It is also compared to a mix containing MK and another containing the mixture of $\mathrm{CCP}$ and MK.

4. The microstructure of $\mathrm{CCP}$ and of the concrete mixes are analyzed using thermogravimetric analysis and scanning electromicroscope to get an understanding of the observed phenomena.

All the samples described in step 2-4 are tested for compressive strength, frost resistance and freeze-thaw resistance, as it can be seen in Fig. 1. The samples of step 1 are subjected to compressive strength test. Besides these, thermogravimetric analysis was performed on all the samples.

\section{Experimental}

\section{Cement mortars}

Three different cement mortars were used for the experiments in the first step of our research (see "Research plan" section) that are described in Table 1. 


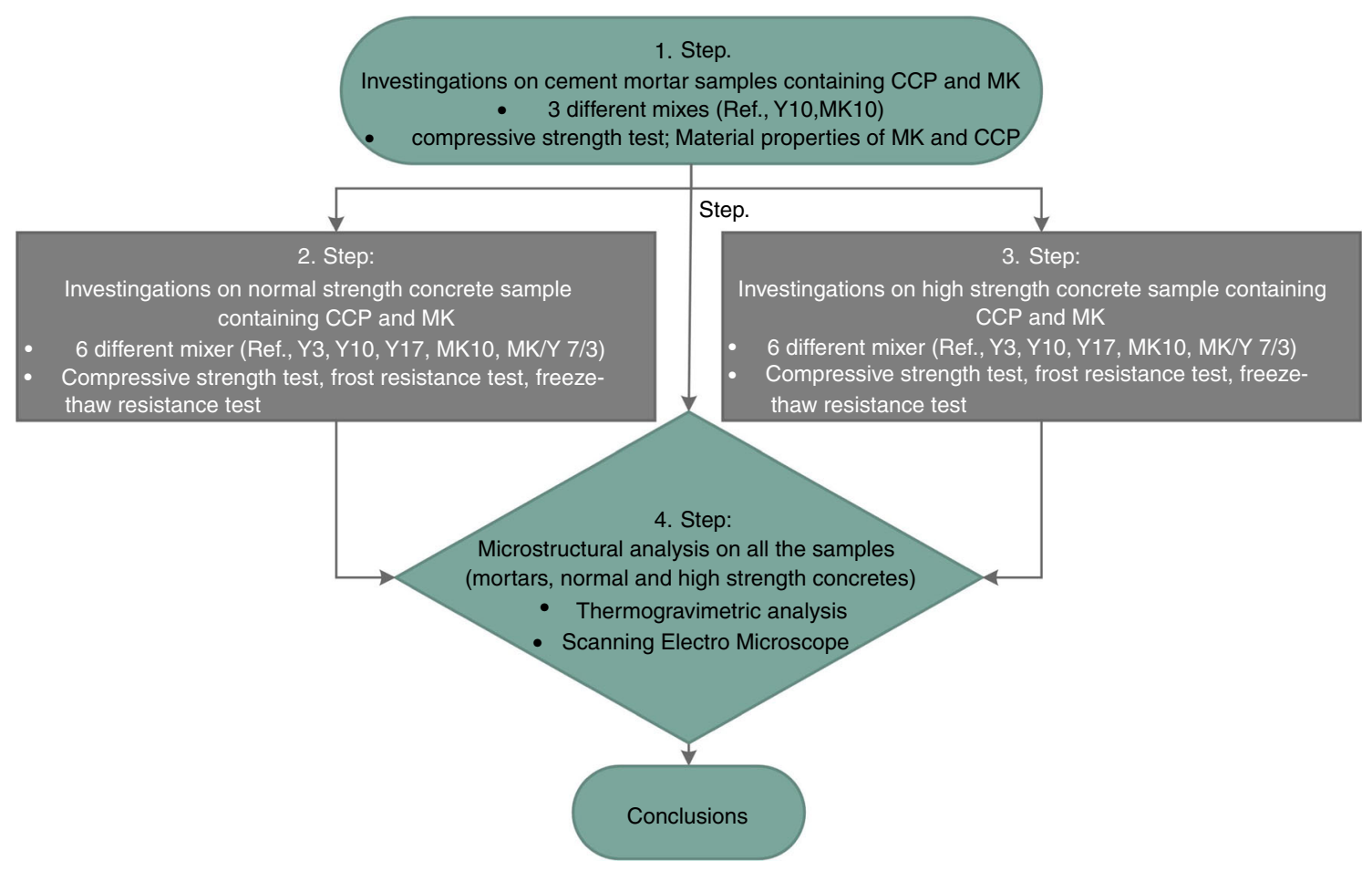

Fig. 1 Research steps flowchart

Table $1 \mathrm{CCP}$ and MK proportions in the different mortar samples

\begin{tabular}{lll}
\hline Notation & Description & Performed laboratory tests on the samples \\
\hline Reference & Reference mix, 100\% cement & Compressive strength test and thermogravimetric analysis at different ages of the samples \\
Y10 & $10 \%$ of cement was substituted by CCP & \\
MK10 & $10 \%$ of cement was substituted by MK & \\
\hline
\end{tabular}

All samples contained CEM I $42.5 \mathrm{~N}$-type cement and only the necessary amount of water $(v / c=0.5)$ was added. $40 \mathrm{~mm} \times 40 \mathrm{~mm} \times 160 \mathrm{~mm}$ prisms were cast from the above-described mortar and their density and flexural- and compressive strengths were determined.

In the present research, one type of $\mathrm{CCP}$ with original gross dry body density (of the block) of $440 \mathrm{~kg} \mathrm{~m}^{-3}$ was applied. The choice was based on business sales statistics that were received from the manufacturer company. It was taken into consideration to test the other available types, but this parameter was kept unchanged during present tests. It is planned to be tested in further research phases with demolished CCP waste used as aggregate as well. The most important properties of the original CCP block (from which was obtained), based on its declaration of performance:

- Mean compressive strength: $3.0 \mathrm{~N} \mathrm{~mm}^{-2}$,

- Thermal conductivity: $0.125 \mathrm{~W} \mathrm{mK}^{-1}$,

- Water vapor permeability: $5 / 10$.
It is important to mention that the applied aggregate size of the CCP belongs to the $0 / 0.09$ fraction (particle size lower than $0.09 \mathrm{~mm}$ ), while the MK does to the 0/0.018 fraction. The particle sizes were determined using laser diffraction analysis. The specific surface area of CCP is lower with an order of magnitude compared to MK, as it is shown in Table 2.

The density and porosity of $\mathrm{CCP}$ and $\mathrm{MK}$ were also determined based on the Hungarian national standard [29]. The amount of CCP did not affect the workability of the mixes. The body density of CCP is increasing with its fineness, as shown in Fig. 2. While, in brick form, it is only $700 \mathrm{~kg} \mathrm{~m}^{-3}$, then in powder form it is already $2000 \mathrm{~kg} \mathrm{~m}^{-3}$, which is still less, than concrete's density. Based on this figure, the porosity of CCP decreased with grinding and pulverizing. Figure 8 shows that there are still pores in the powder and it could be further pulverized; however, these small pores could be advantageous for frost resistance. In the present research, the powder was not further pulverized, and it was applied as it arrived at the 
Table 2 Specific surface area of MK and CCP determined by laser diffraction analysis

\begin{tabular}{lll}
\hline Material & Metakaolin & Cellular concrete powder \\
\hline Specific surface area $/ \mathrm{cm}^{2} \mathrm{~cm}^{-3}$ & 28,695 & 2513 \\
\hline
\end{tabular}

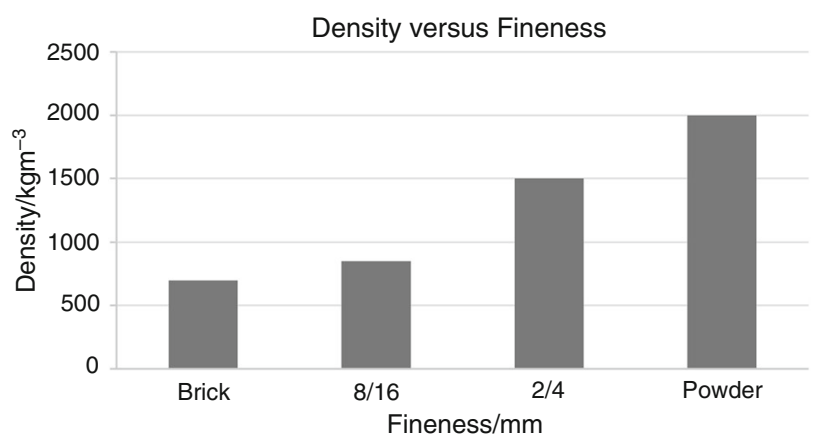

Fig. 2 Density $/ \mathrm{kg} \mathrm{m}^{-3}$ versus fineness $/ \mathrm{mm}$ of CCP

laboratory. The bulk density of the MK in the applied powder form was $550 \mathrm{~kg} \mathrm{~m}^{-3}$.

The main oxide components (in percentage) of the two supplementary materials and the applied cement were the following:

- Cement $\mathrm{SiO}_{2} \rightarrow 19.33 \% ; \mathrm{CaO} \rightarrow 63.43 \% ; \mathrm{MgO} \rightarrow$ $1.45 \% ; \quad \mathrm{Fe}_{2} \mathrm{O}_{3} \rightarrow 3.42 \% ; \quad \mathrm{Al}_{2} \mathrm{O}_{3} \rightarrow 4.67 \% ; \quad \mathrm{SO}_{3} \rightarrow$ $2.6 \%$

- $M K \mathrm{SiO}_{2} \rightarrow 53.0 \% ; \mathrm{Al}_{2} \mathrm{O}_{3} \rightarrow 41.7 \% ; \mathrm{Fe}_{2} \mathrm{O}_{3} \rightarrow 0.52 \%$

- $C C P \mathrm{SiO}_{2} \rightarrow 54.3 \% ; \mathrm{CaO} \rightarrow 22.8 \% ; \mathrm{Al}_{2} \mathrm{O}_{3} \rightarrow 5.1 \%$; $\mathrm{SO}_{3} \rightarrow 4.9 \%$

\section{Concrete mix design}

Two basic concrete mixes were used during our experiments, which are described with more details in [27, 30]. The first concrete mix was designed to have a relatively low resistance against freezing. The aimed strength class was $\mathrm{C} 20 / 25$ in case of the reference mix, which is a widely used concrete strength class in the industry. A concrete from the C20/25 strength class is usually appropriate for regular civil engineering structures, the reason why stronger concretes are used is the durability issues of these structures. However, if a concrete could be designed, which belongs to the $\mathrm{C} 20 / 25$ strength class and has better durability performance, then it could be applied by the industry.

Three nominal grading fractions according to European Standard EN 12620:2002+A1:2008 [31] were used: sand $0 / 4 \mathrm{~mm}$, small gravel $4 / 8 \mathrm{~mm}$ and medium gravel $8 / 16 \mathrm{~mm}$. The aggregate used in the reference mix was normal quartz gravel with $d_{\max }=16$ and distribution as follows (Table 3).

The reference mix's design is described in Table 4.
Table 3 Aggregate particle size distribution of the C20/25 class reference concrete

\begin{tabular}{lll}
\hline Aggregate diameter/mm & Distribution $/ \%$ & Actual mass $/ \mathrm{kg} \mathrm{m}^{-3}$ \\
\hline $0 / 4$ & 47 & 936 \\
$4 / 8$ & 25 & 498 \\
$8 / 16$ & 28 & 557 \\
\hline
\end{tabular}

Table 4 Mix design of the reference mix

\begin{tabular}{llll}
\hline Component & & Distribution/- & Mass $/ \mathrm{kg} \mathrm{m}^{-3}$ \\
\hline Cement & CEM I 42.5 N & - & 270 \\
Water & $w / c=0.57$ & - & 154 \\
Aggregate & $0 / 4 / \mathrm{mm}$ & 0.47 & 936 \\
& $4 / 8 / \mathrm{mm}$ & 0.25 & 498 \\
& $8 / 16 / \mathrm{mm}$ & 0.28 & 557 \\
Sum & & 1 & 2415 \\
\hline
\end{tabular}

CEM I $42.5 \mathrm{~N}$-type cement $\left(270 \mathrm{~kg} \mathrm{~m}^{-3}\right)$ was used, water-to-cement ratio was 0.57 in case of the reference mix and superplasticizers were not used. The above-detailed mixture was used as the reference mix, in which a given amount of cement was substituted by CCP (or MK) or to which a given amount of CCP (or MK) was added. Finally, there were six different mixes.

Table 5 shows that the present research was designed to investigate the effect of CCP with different proportions as well as the interaction of MK with CCP.

The other reference mix was designed to be a highstrength concrete with the strength class around C60/75 (for more detailed description of the mix, see [27]). This mix was used to see that the relations observed in case of the first mix (normal-strength concrete) are also true in case of a high-strength, high frost resistance concrete. The aggregate particle size distribution of the high-strength concrete mix can be seen in Table 6 .

The maximum aggregate diameter was $16 \mathrm{~mm}$, and CEM I $42.5 \mathrm{~N}$-type cement $\left(325 \mathrm{~kg} \mathrm{~m}^{-3}\right.$ together with the SCM) was used with 0.40 water-to-cement ratio. The dosages (in percentage) of CCP and MK were the same as in case of the normal-strength concrete (Table 7).

From the above-described mixes, 100-mm and 150-mm edge length cubes were cast and used during the laboratory experiments. 
Table $5 \mathrm{CCP}$ and MK proportions in the different mixes of the normal-strength concrete samples

\begin{tabular}{|c|c|c|c|c|c|}
\hline Notation & Description & $\begin{array}{l}\text { Cement/ } \\
\mathrm{kg} \mathrm{m}^{-3}\end{array}$ & $\begin{array}{l}\mathrm{CCP} / \\
\mathrm{kg} \mathrm{m}^{-3}\end{array}$ & $\begin{array}{l}\mathrm{MK} / \\
\mathrm{kg} \mathrm{m}^{-3}\end{array}$ & Performed laboratory tests on the samples \\
\hline Reference & $\begin{array}{l}\text { Reference mix, as it described } \\
\text { above }\end{array}$ & 270 & 0 & 0 & $\begin{array}{l}\text { Compressive strength test, frost resistance test, freeze-thaw } \\
\text { resistance test and thermogravimetric analysis }\end{array}$ \\
\hline Y3 & $\begin{array}{l}3 \% \text { of cement was substituted by } \\
\text { CCP }\end{array}$ & 261.9 & 8.1 & 0 & \\
\hline Y10 & $\begin{array}{l}10 \% \text { of cement was substituted by } \\
\text { CCP }\end{array}$ & 243 & 27 & 0 & \\
\hline Y17 & $\begin{array}{l}17 \% \text { of cement was substituted by } \\
\mathrm{CCP}\end{array}$ & 224.1 & 45.9 & 0 & \\
\hline MK10 & $\begin{array}{l}10 \% \text { of cement was substituted by } \\
\text { MK }\end{array}$ & 243 & 0 & 27 & \\
\hline $\begin{array}{c}\mathrm{MK} / \mathrm{Y} \\
7 / 3\end{array}$ & $\begin{array}{l}10 \% \text { of cement was substituted } 7 \% \\
\text { by MK and } 3 \% \text { by CCP }\end{array}$ & 243 & 8.1 & 18.9 & \\
\hline
\end{tabular}

Table 6 Aggregate particle size distribution of the C60/75 class reference concrete

\begin{tabular}{lll}
\hline Aggregate diameter/mm & Distribution/\% & Actual mass $/ \mathrm{kg} \mathrm{m}^{-3}$ \\
\hline $0 / 4$ & 40 & 774 \\
$4 / 8$ & 25 & 484 \\
$8 / 16$ & 35 & 677 \\
\hline
\end{tabular}

\section{Laboratory tests}

This section shortly summarizes the applied laboratory tests.

\section{Strength and durability tests}

The compressive strength of the concretes was determined at 28 days of age after wet curing (stored for 14 days under water and 14 days on dry laboratory air) of the $150-\mathrm{mm}$ edge length specimens according to European Standard EN 12390-3:2009 [32]. The uniaxial compressive strength test was performed in an Alpha 3-3000 S hydraulic press with $11.25 \mathrm{kN} \mathrm{s}^{-1}$ (static) loading rate.

The samples were subjected to frost resistance test as well. Compressive strength test was also carried out on samples, which were subjected to freezing cycles to determine their frost resistance. Frost resistance test is usually recommended by standards for concretes applied in vertical structures, like pillars and walls. The test was carried out based on the MSZ 4715/3-72 standard [33].

Freeze-thaw resistance test is the most common procedure to quantify the durability of concrete [34]. During the freeze-thaw resistance test, the samples are subjected to alternating freezing and thawing cycles based on the recommendations of the CEN/TS 12390-9:2007 standard [35]. This test is recommended for concretes used in

Table $7 \mathrm{CCP}$ and MK proportions in the different mixes of the high-strength concrete samples

\begin{tabular}{|c|c|c|c|c|c|}
\hline Notation & Description & $\begin{array}{l}\text { Cement/ } \\
\mathrm{kg} \mathrm{m}^{-3}\end{array}$ & $\begin{array}{l}\mathrm{CCP} / \\
\mathrm{kg} \mathrm{m}^{-3}\end{array}$ & $\begin{array}{l}\mathrm{MK} / \\
\mathrm{kg} \mathrm{m}^{-3}\end{array}$ & Performed laboratory tests on the samples \\
\hline Reference & $\begin{array}{l}\text { Reference mix, as it described } \\
\text { above }\end{array}$ & 325 & 0 & 0 & $\begin{array}{l}\text { Compressive strength test, frost resistance test, freeze-thaw } \\
\text { resistance test and thermogravimetric analysis }\end{array}$ \\
\hline $\mathrm{Y} 3$ & $\begin{array}{l}3 \% \text { of cement was substituted by } \\
\text { CCP }\end{array}$ & 315.25 & 9.75 & 0 & \\
\hline Y10 & $\begin{array}{l}10 \% \text { of cement was substituted by } \\
\text { CCP }\end{array}$ & 292.5 & 32.5 & 0 & \\
\hline Y17 & $\begin{array}{l}17 \% \text { of cement was substituted by } \\
\text { CCP }\end{array}$ & 269.75 & 55.25 & 0 & \\
\hline MK10 & $\begin{array}{l}10 \% \text { of cement was substituted by } \\
\text { MK }\end{array}$ & 292.5 & 0 & 32.5 & \\
\hline $\begin{array}{c}\mathrm{MK} / \mathrm{Y} \\
7 / 3\end{array}$ & $\begin{array}{l}10 \% \text { of cement was substituted } 7 \% \\
\text { by MK and } 3 \% \text { by CCP }\end{array}$ & 292.5 & 9.75 & 22.75 & \\
\hline
\end{tabular}


horizontal structures, like pavements. First, the originally $100 \times 100 \times 100 \mathrm{~mm}$ samples are cut in half. The test can be performed on three different surfaces of the specimen: sawn surface, top surface, surface cast against formwork. The CEN standard recommends the evaluation based on the results of the sawn surface. After the freeze-thaw cycles, the specimens are taken out from the freezer and the scaled material from the tested surface is removed and weighed. The more measured mass the higher the scaling and the lower the freeze-thaw resistance.

\section{Microstructural analysis}

The most widely applied method for studying the internal processes occur in cement-based systems is thermogravimetric analysis (TGA). TGA was applied to provide information about the processes (phase transitions, thermal decomposition, etc.) in CCP. In our measurements, the following data were recorded and plotted over time, as it can be seen in figures in "Results and discussion" section:

- the temperature $(T)$ of the investigated material $/{ }^{\circ} \mathrm{C}$,

- the thermogravimetric (TG) curve/mg,

- the first derivative of the TG curve (DTG) $/ \mathrm{mg} \mathrm{s}^{-1}$,

- and the differential thermal analysis (DTA) $c$ urve $/{ }^{\circ} \mathrm{C}$.

The measurements were performed using a MOM Q-1500 D type derivatograph with a Derill converter, applying $10 \mathrm{~K} \mathrm{~min}^{-1}$ heating rate. The tested material was taken from the middle of the samples.

Besides that, the surface topography was investigated by Scanning Electron Microscope (SEM) method, to have a picture about the microstructure of CCP.

\section{Results and discussion}

In the present section, the results of the laboratory tests are presented and discussed.

\section{Results of long-time measurements on mortars}

First, the effect of CCP on cement mortars was investigated as it was mentioned in "Research plan" section. The results in different ages can be seen in Table 8 .

The results show (Table 8 ) that in early ages all the added materials (CCP, MK) are decreasing the compressive strength; however, after a given time ( $\sim 90$ days), their effect on strength becomes positive. The thermogravimetric analysis shows that in the curves of the derivatograms presented in Fig. 3, there are three characteristic, mass-changing endothermic transformations:
Table 8 Compressive strength results of the mortar prism samples

\begin{tabular}{lllllc}
\hline \multirow{5}{*}{} & \multicolumn{5}{l}{ Compressive strength/ $\mathrm{N} \mathrm{mm}^{-2}$} \\
\cline { 2 - 6 } & 2 days & 7 days & 28 days & 90 days & 180 days \\
\hline Reference & 53.1 & 72.6 & 74.2 & 76.4 & 86.1 \\
Y10 & 47.3 & 65.4 & 73.9 & 83.4 & 84.8 \\
MK10 & 50.3 & 68.6 & 72.0 & 94.0 & 104.0 \\
\hline
\end{tabular}

1. Peak The evaporation of the unbounded water content of the sample furthermore the loss of gypsum and ettringite phase in the range of $80-240{ }^{\circ} \mathrm{C}$,

2. Peak The decomposition of the calcium hydroxide phase with loss of water at $430-540{ }^{\circ} \mathrm{C}$ [36]: $\mathrm{Ca}(\mathrm{OH})_{2} \rightarrow \mathrm{CaO}+\mathrm{H}_{2} \mathrm{O}$,

3. Peak Mainly carbon dioxide loss of calcium carbonate, which was the result of the carbonation of calcium hydroxide, above $600{ }^{\circ} \mathrm{C}: \mathrm{CaCO}_{3} \rightarrow \mathrm{CaO}+\mathrm{CO}_{2}$.

The decrease in the first peak's size clearly shows the decrease in unbounded water content (mixing water) in the sample and indicates the increase in $\mathrm{Ca}(\mathrm{OH})_{2}$ content. Similar behavior was observed on the Y10 and MK10 samples as well.

The calculated mass losses of the above-mentioned three degradation processes are listed in Table 9. Based on the loss of water resulting from the decomposition of calcium hydroxide, the amount of portlandite present in the system at a given age was calculated, which is also shown in Table 9. The table highlights the mass loss in the range of $600-800{ }^{\circ} \mathrm{C}$ that is the carbon dioxide loss of calcium carbonate, which was indicated by the (3) peak mildly observable in Fig. 3 as well.

The $\mathrm{Ca}(\mathrm{OH})_{2}$ content of the different mortars over time is shown in Fig. 4.

It can be seen in Fig. 4 that in all ages the reference mortar has the highest $\mathrm{Ca}(\mathrm{OH})_{2}$ content, while the MK10 mortar has the lowest $\mathrm{Ca}(\mathrm{OH})_{2}$ content. The $\mathrm{Y} 10$ mortar, where $10 \%$ of cement is substituted by CCP (which can be apprehended as an inert material), is between the other two mortars but in time it gets closer to the reference mortar. In a strength point of view, until 28 days of age the reference has the highest compressive strength. Until 28 days of age, as the $\mathrm{Ca}(\mathrm{OH})_{2}$ content increasing, the strength increasing as well in all mixes with similar tendency. Until the age of 28 days, the strength of the three mixes increases similarly. The 28-day compressive strength, which is used in the standards, is almost the same for all the mortars. After 28 days, the compressive strength of the Y10 mortar increases with the same rate as the reference mix and their $\mathrm{Ca}(\mathrm{OH})_{2}$ content reaches the same level, as it can be seen in Fig. 5. Meanwhile, in case of the MK10, the rate of 
Fig. 3 Result of the TG analysis (time vs. temperature and mass change) of the reference mortar after mixing ( 0 days $-\mathbf{a}$ and at 180 days $\mathbf{b})$ of age (a)

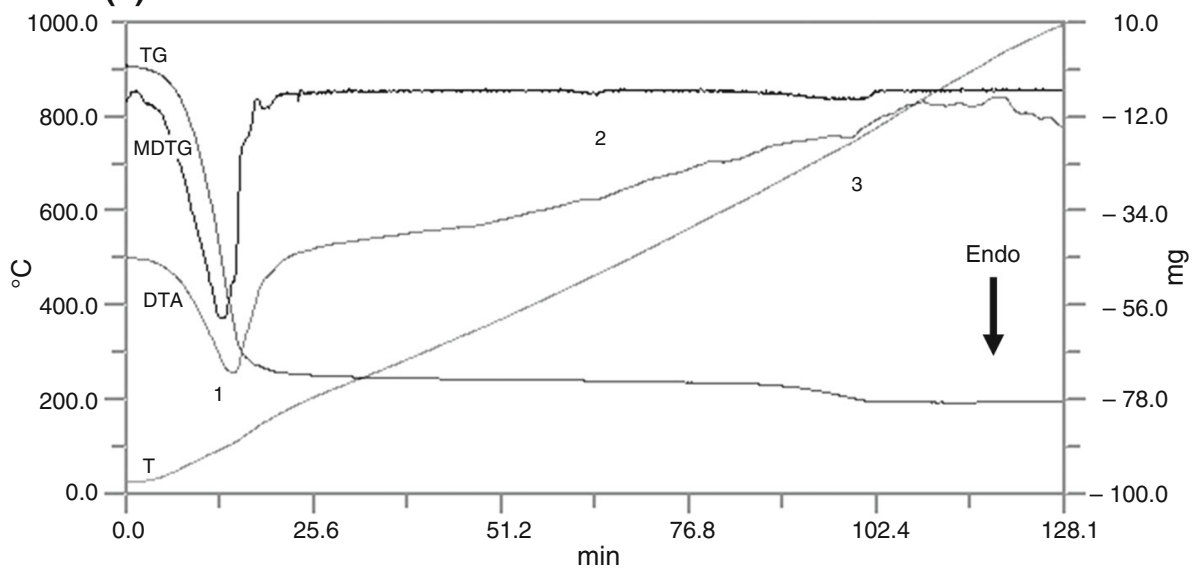

(b)

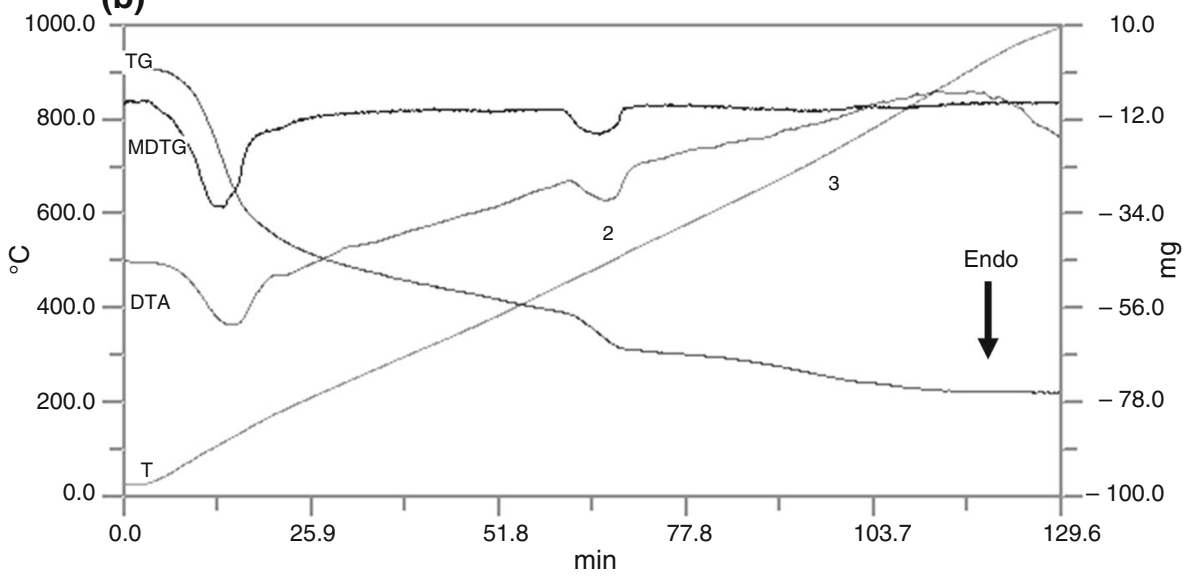

Table 9 Mass loss and amount of portlandite in the samples from 0 to 180 days of age

\begin{tabular}{|c|c|c|c|c|c|c|c|}
\hline & \multirow[t]{2}{*}{ Thermal decomposition range $/{ }^{\circ} \mathrm{C}$} & \multicolumn{6}{|l|}{ Mass loss/\% } \\
\hline & & After mixing & 2 days & 7 days & 28 days & 90 days & 180 days \\
\hline \multirow[t]{5}{*}{ Reference } & $20-240$ & 23.68 & 15.74 & 15.61 & 14.89 & 15.85 & 15.52 \\
\hline & $430-540$ & 0.14 & 2.5 & 2.85 & 2.87 & 2.75 & 3.05 \\
\hline & $600-800$ & 1.38 & 1.54 & 1.79 & 1.29 & 1.51 & 2.59 \\
\hline & $20-800$ & 26.02 & 23.92 & 24.76 & 23.46 & 23.71 & 25.17 \\
\hline & $\mathrm{Ca}(\mathrm{OH})_{2}$ amount & 0.58 & 10.27 & 11.71 & 11.8 & 11.9 & 12.54 \\
\hline \multirow[t]{5}{*}{ Y10 } & $20-240$ & 24.9 & 17.32 & 17.88 & 15.53 & 14.91 & 16.07 \\
\hline & $430-540$ & 0.29 & 2.13 & 2.63 & 2.61 & 2.8 & 3.14 \\
\hline & $600-800$ & 1.07 & 2.13 & 1.91 & 1.83 & 2.03 & 1.73 \\
\hline & $20-800$ & 27.67 & 24.55 & 26.19 & 24.17 & 23.99 & 25.74 \\
\hline & $\mathrm{Ca}(\mathrm{OH})_{2}$ amount & 1.19 & 8.75 & 10.5 & 10.72 & 11.51 & 12.45 \\
\hline \multirow[t]{5}{*}{ MK10 } & $20-240$ & 22.63 & 10.12 & 16.41 & 16.07 & 15.57 & 16.18 \\
\hline & $430-540$ & 0.16 & 1.99 & 2.65 & 2.36 & 2.45 & 2.43 \\
\hline & $600-800$ & 1.14 & 1.2 & 1.32 & 1.39 & 1.54 & 2.09 \\
\hline & $20-800$ & 24.72 & 24.2 & 24.23 & 24.4 & 24.13 & 24.73 \\
\hline & $\mathrm{Ca}(\mathrm{OH})_{2}$ amount & 0.66 & 8.18 & 9 & 9.7 & 10.07 & 9.99 \\
\hline
\end{tabular}




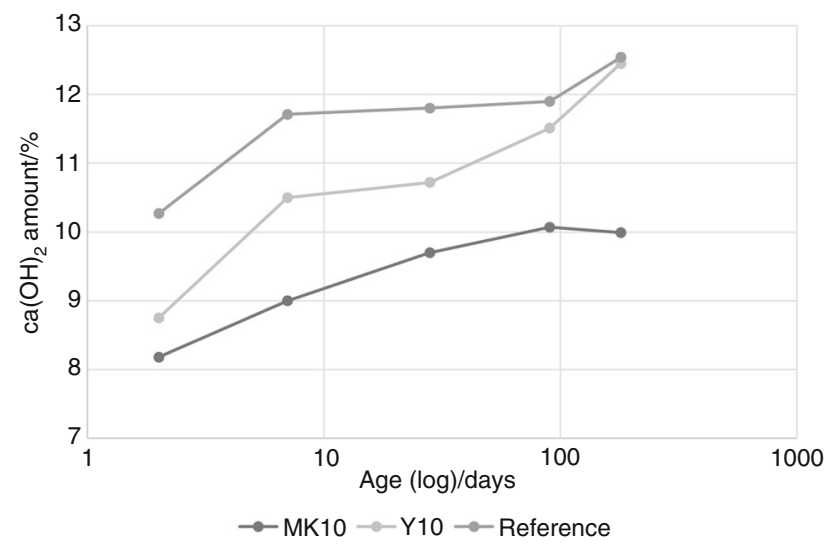

Fig. $4 \mathrm{Ca}(\mathrm{OH})_{2}$ amount of the three mortars at different ages

$\mathrm{Ca}(\mathrm{OH})_{2}$ content increase is slighter compared to the other two mortars; however, its compressive strength is increasing with a higher rate than previously. In that phase, the effect of the supplementary material is more significant than the hardening of cement. Based on that, it can be seen that the CCP is not working similarly to a traditional SCM (metakaolin), its behavior is closer to a filler material. The figure shows that after 90 days of age the $\mathrm{Ca}(\mathrm{OH})_{2}$ content of MK10 is slightly decreasing. The reason behind it is that MK has high reactivity with $\mathrm{Ca}(\mathrm{OH})_{2}$, but low reaction rate, thus it requires more time to form $\mathrm{CSH}$ crystals that integrate into the crystal structure of concrete. In case of Y10, this behavior cannot be seen which also indicates that CCP does not work as a traditional SCM, there is no hydration of CCP. However, CCP does not decrease the $\mathrm{Ca}(\mathrm{OH})_{2}$ content in long term, thus the alkalinity of the mix remains unchanged, which is advantageous against corrosion when the concrete is applied together with steel reinforcing bars. It means that $\mathrm{CCP}$ can be applied in higher amount compared to MK. Based on the previous experiences of the authors, from MK more than $20 \%$ is not recommended, because it can highly decrease the alkalinity of the concrete.

The density and flexural strength measurement data were recorded as well, but the results did not indicate any finding.

\section{Compressive strength results of the concrete samples}

\section{Normal-strength concrete with CCP substituting cement}

As it was mentioned in "Research plan" section, it was investigated, what effect the CCP has, if it is added to the mix of a normal-strength concrete. The C20/25 concrete was chosen to be used in the experiments, because on a concrete with relatively low compressive strength and low frost resistance, the effect of CCP could be significant and easily observed. CCP in different amounts was mixed to the reference mix by substituting a given amount of cement. Based on the literature data [27] from 3 to $17 \%$ of the cement amount was substituted. In Fig. 6, the compression test results are presented, which show that even a small amount (3\%) of CCP could increase the compressive strength of NSC. With the increase in the amount of CCP in the mix, the compressive strength is increasing as well, until a given point around $10 \%$. 17\% of CCP is already showed less advantageous performance, than the $10 \%$, which increased the compressive strength with $34 \%$. Based on the laboratory tests the Y10 mix could be called as a rough optimum. Similar value for SCMs (metakaolin and silica fume) was found in [27]. It is important to see that the Y10 mix increased the strength and it also decreased the amount of cement in the mix by $10 \%$, which in large scale could be economically highly beneficial.

The final aim of this research was to determine whether $\mathrm{CCP}$ could be used as an alternative to traditional SCMs or not. Therefore, MK (a typically used SCM) was mixed to
Fig. 5 Compressive strength of the reference, MK10 and Y10 mortars at different ages

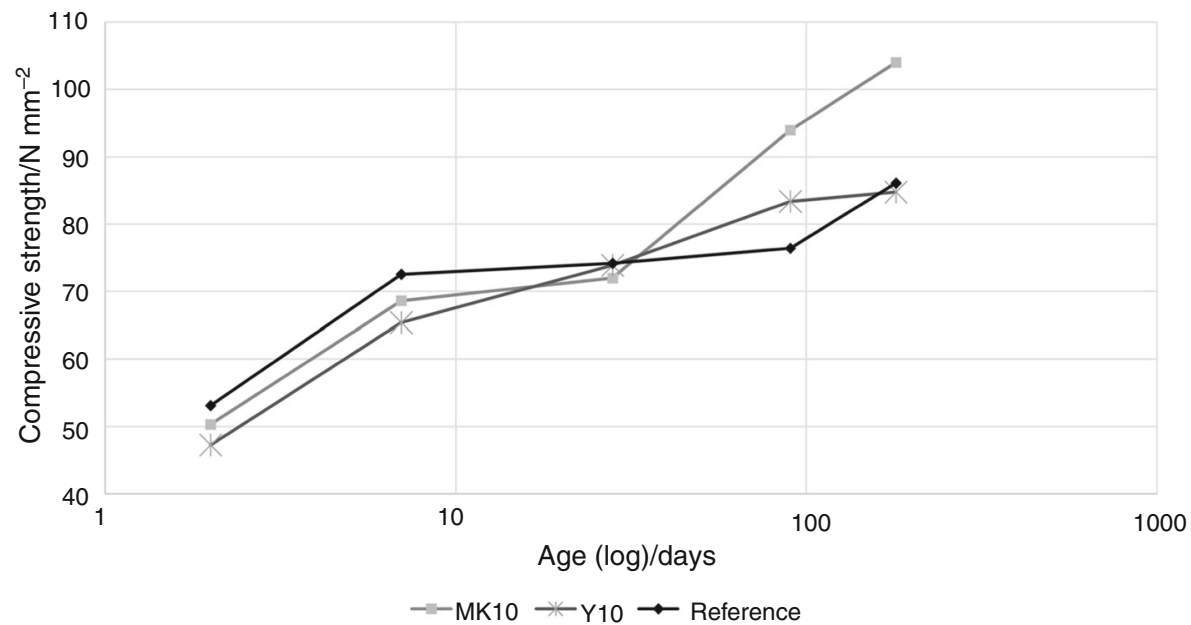




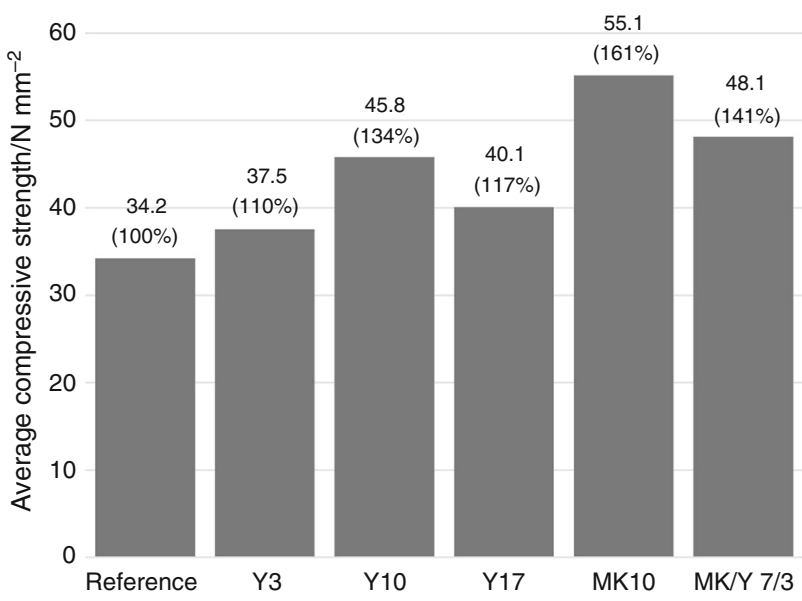

Fig. 6 Compressive strength of the normal-strength concretes, if cement substituted by CCP or by MK in different amounts (average 28 days)

the reference mix. $10 \%$ (substituting cement) dosage of MK was applied, based on the final conclusions of [27]. Besides that, the interaction of the MK and CCP was tested. Figure 6 shows that the MK10 was the most advantageous, it increased highly (by 61\%) the compressive strength of NSC. The mix of the CCP and MK increased the strength as well, however not as much as the MK10 mix. Comparing to the Y10 mix, the MK10 mix is still superior; however, CCP is a freely available construction waste, which does not require any preparation before mixing, while nowadays metakaolin is produced in factories.

The impressing performance of the CCP could be explained by its form, which is a fine powder (made of a cement-based material) that increases the specific area of the aggregates and works as a filling material (see "Cement mortars" section). CCP came to the laboratory in powder form and its density was close to the density of the applied cement. By adding this fine powder to the concrete mix a more favorable aggregate frame is developed, which contains more fine particles. At this $w / c$ ratio, CCP decreased the porosity of the concrete as well. This physical effect is a reason behind the advantageous performance of the mixes containing CCP. The maximum strength increase was $34 \%$ (Y10 mix), which was possible using a filler material (CCP). Most SCMs work as a filling material too and their particle size is smaller than the particle size of cement. It is not the case for CCP, which from this standpoint could not be considered as a real SCM. Nevertheless, CCP is still increasing the compressive strength of concrete. It would be interesting to see its effect, if it is pulverized to the particle size of traditional SCMs. Traditional SCMs has a chemical effect as well (their reaction with $\left.\mathrm{Ca}(\mathrm{OH})_{2}\right)$, which was not observed in case of $\mathrm{CCP}$ and can be explained by the size of the CCP particles that are an order of magnitude higher than the MK particles. MK was able to increase the strength to a greater extent $(61 \%)$, because it works as a filler material and as a hydraulic component as well. The MK/Y 7/3 mix had slightly better performance than the Y10 mix, but worse than the MK10 mix. The amount of filling material was the same here (10\% was substituted), but only a lower amount (7\%) was a hydraulic material. Based on the literature [27] it is advisory to apply at least $10 \%$ to reach beneficial results. If only $7 \%$ of cement is substituted by $\mathrm{MK}$, it is not able to exert its favorable effects or these effects are perceivable only later (not at the age of 28 days).

To get a better understanding of the processes taking place in the material a thermogravimetric (TG/DTG/DTA) analysis was performed on CCP. In Fig. 7, the result of the thermogravimetric measurements performed on CCP can be seen. In the figure, an exothermic peak is visible around $110 \mathrm{~min}\left(700^{\circ} \mathrm{C}\right)$. Cellular concrete was autoclaved above $180{ }^{\circ} \mathrm{C}$ and there tobermorite $\left(\mathrm{C}_{5} \mathrm{~S}_{6} \mathrm{H}_{5}\right.$ - special type of $\mathrm{CSH}$ ) was developed, which favorably effects the strength of concrete. The ideal CSH frame of tobermorite, as a filling material, increases the strength of concrete, as it was observable in the compressive strength measurements.

The surface topography was investigated by Scanning Electron Microscope (SEM) method, to have a picture about the microstructure of CCP. As shown in Fig. 8, the size of fine particles is within the range of sizes of an ideal filling material. However, larger particles can be seen as well, which contain pores that decrease the strength, although it could be advantageous in a frost resistance point of view. These particles can absorb water into their capillary system, which later works as an inner curing during the hardening of concrete.

\section{High-strength concrete containing CCP and MK}

The previous investigations were repeated on a highstrength concrete (used as reference mix) as well. The same mix design for the reference mix was used as in [27]. This mix produced a $660 / 75$ class concrete. In this case, by the increase in the amount of CCP the compressive strength decreased. In Fig. 9, it can be seen, that the decrease until $10 \%$ of CCP is not so significant (almost the same in case of the Y3 and Y10 mixes). In case of the Y17 mix, the strength drop was much higher, of $62 \%$ of the strength of the reference mix was reached by the Y17 mix. When MK was added to the mix, it was still able to increase its strength (by 13\%), however not as significantly as in case of the NSC. The MK/Y mix slightly decreased the compressive strength, as it can be seen in Fig. 9.

In [27] the MK10 mix performed even better. There $110.42 \mathrm{~N} \mathrm{~mm}^{-2}$ compressive strength was measured on that mix at 28 days of age. The difference in the results 
Fig. 7 Result of the TG measurements on CCP (time vs. temperature and mass change)

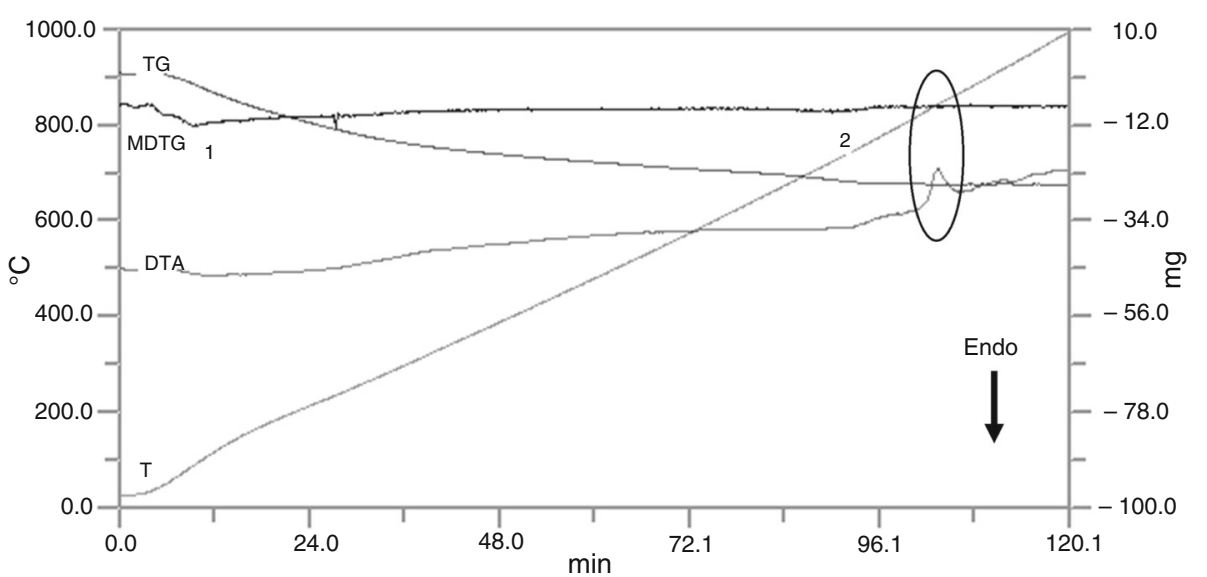

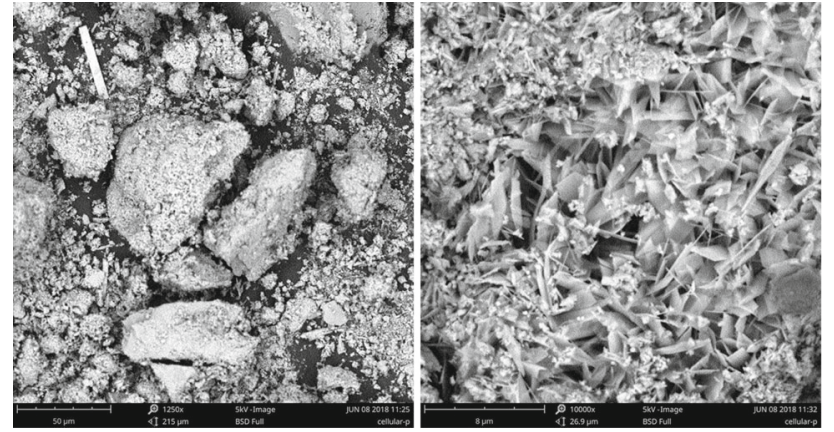

Fig. 8 SEM of CCP at $\times 1250$ (left) and $\times 10,000$ (right) magnification

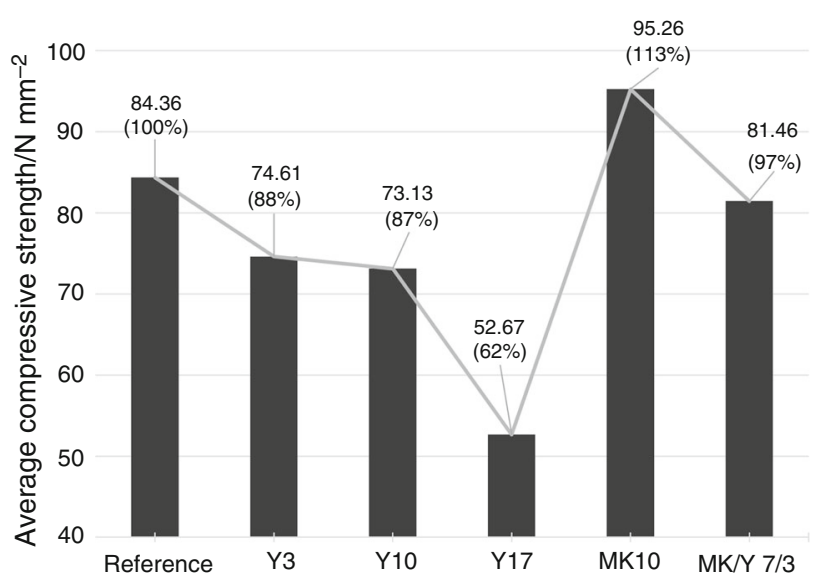

Fig. 9 Compressive strength of the high-strength concretes, if cement substituted by CCP or by MK in different amounts (average 28 days)

presented in [27] and in the present case could be explained by the different quality of MK, because the reference mix compressive strengths were very close to each other.

While in case of NSC, the CCP had positive effect on strength, and in case of HSC, this benefit cannot be observed. This can be caused by the phenomena observed in the literature [25] that if the normal aggregate is substituted by recycled cellular concrete the sulfate content is higher, which can lead to a sulfate swelling that leads to cracking. In the present case part of the cement amount was substituted by cellular concrete. This relatively low amount of substitution caused sulfate swelling as well. In case of NSC, which has higher porosity, this swelling has a positive effect by decreasing the porosity. The swelling particles fill the pores and in the vicinity of the small CCP particles only small forces arise that cannot cause severe damage in the concrete. However, in case of HSC, where the porosity is much lower (low amount and size of pores), there is no room for swelling and higher forces (due to restrained deformations) arise, leading to the failure of the material. As it can be seen in Fig. 9, the more CCP is added the higher the strength decrease was, which can be explained by the higher amount of swelling material. This explains why the $\mathrm{MK} / \mathrm{Y}$ mix has significantly lower strength as well compared to the MK10 mix.

This could explain, why in case of NSC the Y10 mix had the best performance. While in case of the $\mathrm{Y} 3 \mathrm{mix}$, the amount of CCP is not enough to fill the pores and in case of the Y17 mix, the amount of CCP is too high, the Y10 mix contains just enough CCP to fill the pores, but not too much to cause high forces inside the material. Based on that it can be concluded that the optimal CCP amount is dependent on the porosity of concrete. In the present case, this optimum is around $10 \%$ for NSC. If the porosity of the concrete is too low (HSC) the substitution of cement with CCP cannot be advantageous in a compressive strength point of view.

\section{Frost resistance test results}

\section{Normal-strength concrete with CCP added to the mix}

The results of the frost resistance measurements are presented in similar order, as it was in case of the compressive strength results. In Fig. 10, the results of the compressive strength tests are presented after 0 and 150 freezing cycles 
(described in "Strength and durability tests" section) as well as the ratio of the two measurements (indicated by black stripes on the figures). The left axis of the figure belongs to the bars showing the compressive test results, while the secondary axis on the right side of the figure belongs to the ratio of the compressive strengths (after 150 and 0 cycles). A concrete can be considered as frost resistant if the 150 to 0 ratio is above $85 \%$. Thus with these additional materials, a frost resistant concrete could be mixed. Hundred and fifty freezing cycles were applied based on the recommendation of the standard [33], and because in case of the reference mix, only a minor change in compressive strength was observable until 100 cycles.

When the cement was partly substituted by CCP, the values presented in Fig. 10 were measured. The results show a clear tendency for both cases (after 0 and 150 freezing cycles):

- With the increase in the amount of CCP, the compressive strength is increasing as well, until a given point, around $10 \%$.

- After that point, a strong reduction in strength is observed.

The most advantageous of the investigated mixes is the Y10 mix, which significantly increases the strength before and after the freezing cycles as well. It is important to mention that the proportional strength increase is even higher after the freezing cycles compared to the reference mix, meaning that the CCP not only increases the compressive strength itself but the frost resistance as well. This statement is true below a given amount (around 10\%) of $\mathrm{CCP}$ in the mix. When the ratio of the two measured values is considered, the most outstanding is the $\mathrm{Y} 3 \mathrm{mix}(81 \%)$. The Y10 (76\%) mix was also able to increase the ratio of compressive strengths.
The MK10 mix is still advantageous compared to the reference mix after 150 freezing cycles (Fig. 10). However, its proportional strength increase $(40 \%)$ is significantly lower, than it was before the freezing cycles $(67 \%)$. After the freezing cycles, the Y10 mix had better performance than the MK10 mix. The MK/Y mix showed an outstanding performance in this test. After the freezing cycles, it increased the compressive strength by $72 \%$, which is the second best performance among the investigated mixes. This means that the interaction of the CCP and MK can even lead to a better performance, than separately. From a frost resistance viewpoint, the MK10 mix was found to be the weakest ( $60 \%$ 150/0 ratio), while the MK/Y mix had good performance $(84 \%)$. However, quantitatively the compressive strength of the MK10 mix $\left(35 \mathrm{~N} \mathrm{~mm}^{-2}\right)$ is still higher, than the reference mix's $\left(25 \mathrm{~N} \mathrm{~mm}^{-2}\right)$. This means, that the substitution of cement by $\mathrm{MK}$ is still advantageous in a normal-strength concrete, but for durability design purposes, it has to be considered, that its frost resistance is lower, than the mix containing only cement.

The reason behind the outstanding performance of CCP can be seen on the SEM results (Fig. 8). The small CCP particles work as a filling material, while the larger ones introduce ideal size pores in the concrete. The chemical structure of concrete and CCP are very similar and CCP has high internal porosity. Thus, the new CSH crystals, developing during the hydration of concrete, are able to grow amid the already existing CSH crystals of CCP. There is no proof of chemical connection between the newly developed $\mathrm{CSH}$ crystals and the already existing ones, however, based on the test results, the physical connection could be strongly assumed. In case of clay brick, this effect is not present.
Fig. 10 Frost resistance of the normal-strength concretes containing different amount of CCP or MK after 0 and 150 freezing cycles

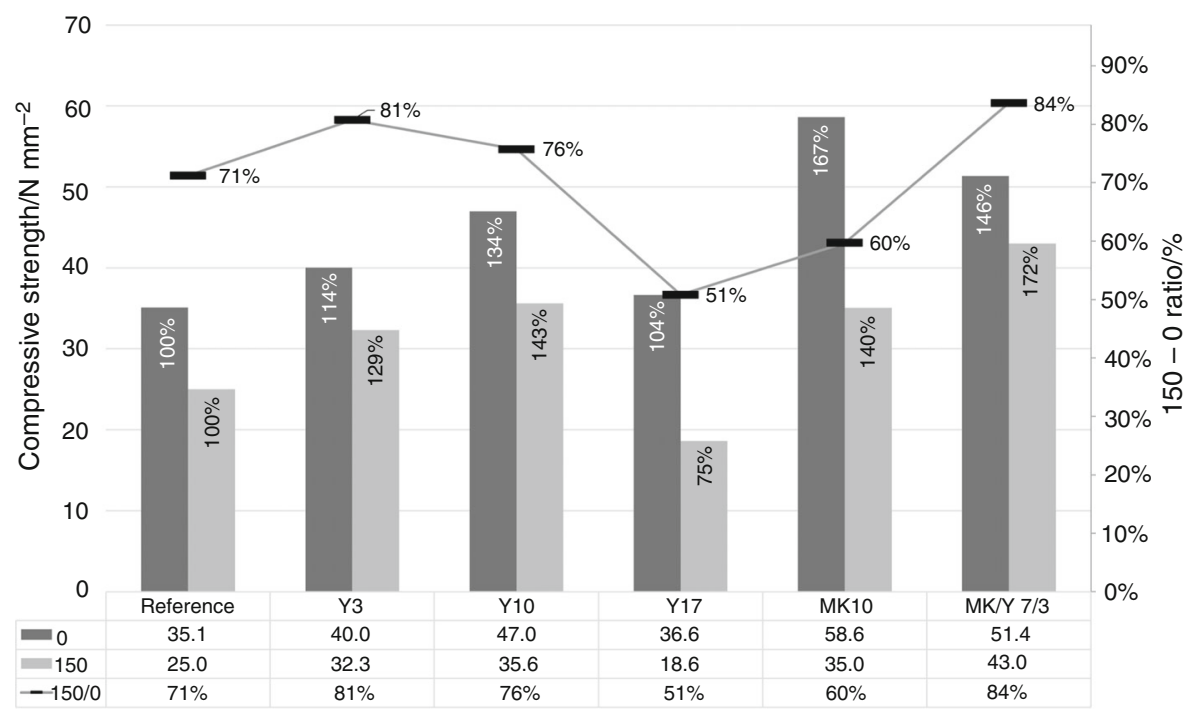




\section{High-strength concrete containing CCP}

Similar trends can be observed in the frost resistance results of the high-strength concrete (containing different amounts of (CP), as it was seen on the compressive strength results (Fig. 11). CCP reduces the compressive strength, and above $10 \%$ dosage, the decrease becomes significant. The results of the Y3 and Y10 mixes are close to each other (within 5\% in both cases). The 150/0 ratio is almost identical for all CCP dosages. The outcome of this test shows that the CCP used as an SCM is not advantageous in case of high-strength concrete, unless the 10-20\% of strength loss is acceptable for lower material cost ( $-10 \%$ cement). Thus, it is not compared in that case to MK.

\section{Freeze-thaw resistance test results}

\section{Normal-strength concrete with CCP added to the mix}

Freeze-thaw test was used to determine the deterioration of the concrete surface and the mass loss of the material was measured. The results of the sawn surfaces were used in the evaluation. The higher amount of mass loss means more deterioration of the surface. The freeze-thaw test with different amount of CCP applied had an interesting result (Fig. 12). CCP addition has resulted in superior resistance compared to the reference mix at the tested relatively low cement substitution ratios. The loss of mass was influenced by the amount of CCP applied in the mix. The higher the cement substitution ratio was, the higher the loss of mass caused by the internal damage due to the freeze-thaw cycles. Similar behavior was observed in [27] for MK.

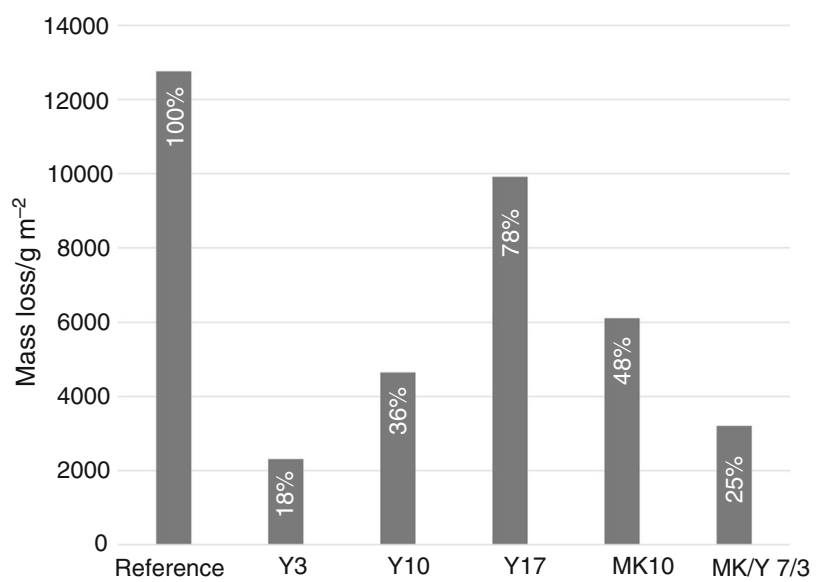

Fig. 12 Mass loss of the normal-strength concretes with $10 \%$ dosage of CCP or MK after 56 freeze-thaw cycles

The Y3 mix only lost $18 \%$ of its mass compared to the reference mix, the Y10 lost 36\%, but the Y17 already lost $78 \%$ that is close to the mass lost by the reference mix. Based on these results, the lower the CCP dosage is the better, however, if cost reduction is significant as well, then the Y10 mix can be advantageous as well. In case of the frost resistance, the optimum of the amount of CCP was found to be around $10 \%$. However, in case of the freezethaw resistance, this optimum is around 3\% (or below). Later more detailed investigation would be necessary to determine this optimum.

Metakaolin addition has resulted in superior resistance compared to the reference mix as well. MK10 has 52\% less mass loss, than the reference mix, which is somewhat higher, than the mass loss of the Y10 mix. The most superior performance was done by the MK/Y mix, as it

Fig. 11 Frost resistance of the high-strength concretes containing different amount of $\mathrm{CCP}$ after 0 and 150 freezing cycles

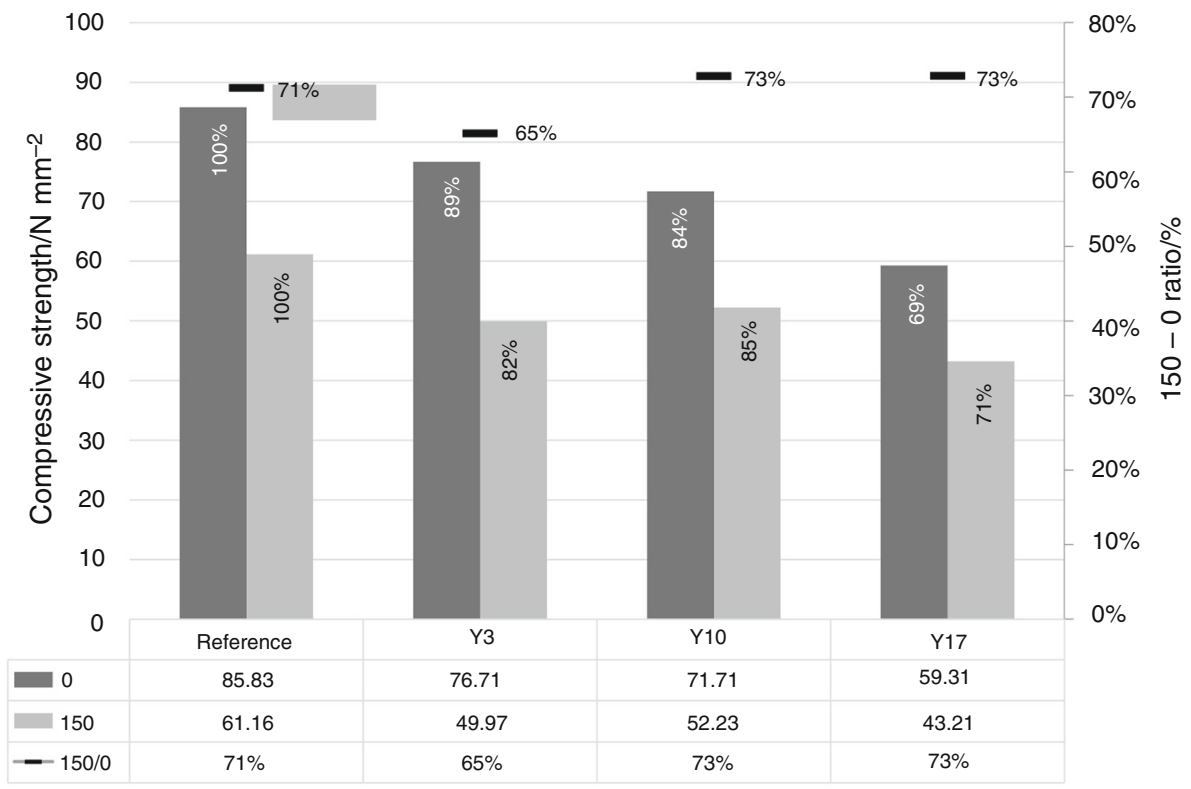


showed in Fig. 12. It can be concluded based on these results and the results presented in "High-strength concrete containing CCP and MK" section that the combined use of MK and CCP could be advantageous for increasing durability of normal-strength concrete. However, the combined MK/Y mix produced still higher loss of mass, than the Y3 mix. Thus, the combination of the two materials is not favorable against the Y3 mix. In Fig. 13, it can be seen that over the freeze-thaw cycles at every cycle the Y3 mix is the most favorable. All applied additives decreased the initial slope of the figures (thus delaying the damage of a structure) and had favorable values in long term (after 56 cycles) as well.

The superior performance of the mixes containing CCP can be explained by the presence of tobermorite crystals $\left(\mathrm{C}_{5} \mathrm{~S}_{6} \mathrm{H}_{5}-\right.$ special type of $\mathrm{CSH}$, which can be found in cellular concrete). Tobermorite is well known for its resistance against salty water (Roman concrete) [37]. In the present case, the tobermorite crystals in the concrete could increase its resistance against the salty water applied during the freeze-thaw resistance test.

\section{High-strength concrete containing CCP and MK}

On high-strength concrete, CCP has very strong effect from the viewpoint of freeze-thaw resistance. Figure 14 shows that smaller amount (Y3 and Y10) of CCP highly decreased $(12 \%$ and $1 \%)$ the loss of mass caused by deterioration. However, higher amount of CCP caused higher mass loss, than it was in case of the reference mix.

MK has advantageous effect as well in correspondence with [27], as it can be seen in Fig. 14. In case of the highstrength concrete, the combination of CCP and MK was not so well performing as it was in case of the normal concrete. In this case, the MK10 mix had much lower mass loss (7\%) compared to the MK/Y mix (22\%). The Y10 mix performed better, than any other mix in this comparison. It is

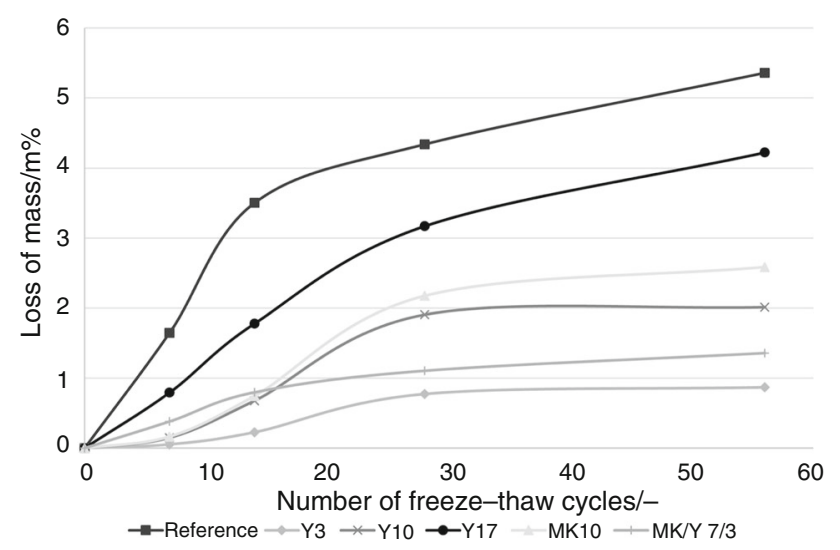

Fig. 13 Change of mass loss during the freeze-thaw cycles for normal-strength concretes

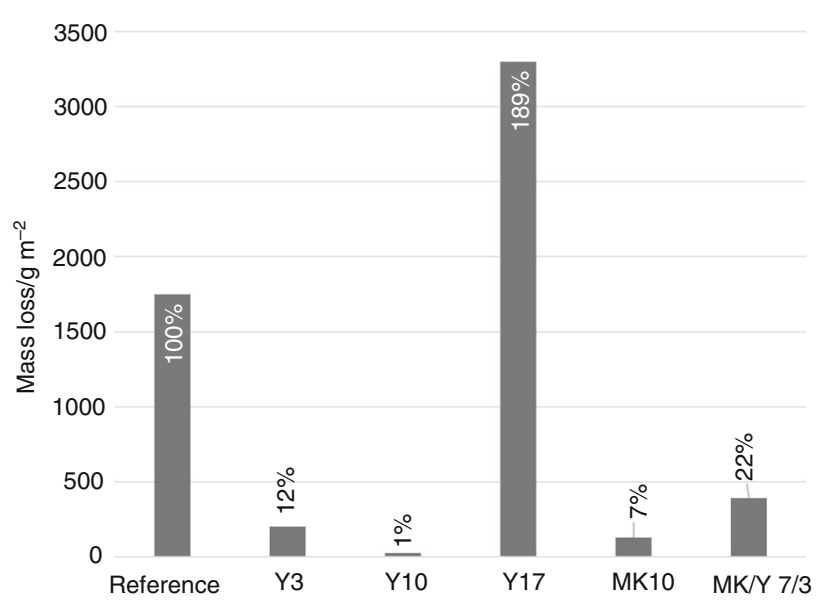

Fig. 14 Mass loss of the high-strength concretes with different amount of CCP or MK after 56 freeze-thaw cycles

important to highlight that both the Y10 and MK10 mixes had mass loss less than $200 \mathrm{~g} \mathrm{~m}^{-2}$, which is the limit value in the standards [35]. These values measured are so small that it is not appropriate to differentiate them (due to the uncertainty of the measurement process), thus as conclusion the following remarks can be declared:

- In case of high-strength concrete, the Y3, Y10 and MK10 mixes all performed exceptionally.

- The Y17 mix had an unfavorable effect.

- The MK/Y mix performed quite well, however compared to the mixes, where only CCP or MK was applied it is unfavorable. Thus, based on the freeze-thaw resistance test results the combination of the two materials is not advantageous, similarly to the literature data, where two SCMs were combined [27].

\section{Conclusions}

The present study introduces a novel application of cellular concrete powder (CCP). Laboratory tests were performed on samples, cast from different concrete mixes containing $\mathrm{CCP}$ and MK and their effect was monitored. Experimental observations of the physical properties and durability of concretes with CCP content are summarized. During the research both individual and combined use of CCP and MK were investigated. Most important aim of this experiment series was to reveal if CCP could be applied advantageously as an SCM in concretes with different strength. CCP was applied as cement substitution in different dosages (3-17\%) and additive to the mix. The main observations and findings are the following:

- CCP works as a filler material (physical effect), not as a traditional SCM, like MK (chemical effect). 
- The amount of $\mathrm{Ca}(\mathrm{OH})_{2}$ is the same in case of the Reference mortar and in case of the Y10 (10\% substitution of cement by $\mathrm{CCP}$ ) mix, which indicates that there is no hydration of CCP during the hardening of concrete.

- CCP was found to be able to increase the compressive strength of normal-strength concrete, which can be explained by the filling effect of the optimal size particles of CCP.

- The optimal dosage (considering compressive strength and maximum possible dosage) of CCP in case of normal-strength concrete is around $10 \%$.

- Compared to MK, CCP was less advantageous from strength point of view; however, it has to be taken into account that CCP is a freely available construction waste and its usage comes with environmental and economic benefits.

- In case of high-strength concrete CCP decreased the compressive strength, while MK was still beneficial, that can be explained by the sulfate swelling of CCP that cause microcracks in the material if its porosity is too low.

- CCP was found to be highly advantageous to increase frost and freeze-thaw resistance of normal-strength concrete. The optimal dosage of CCP was for frost resistance around $10 \%$, while for freeze-thaw resistance around $3 \%$.

- On high-strength concrete, the only real advantage of CCP was the decrease in mass loss during the freezethaw resistance tests (with low dosage). MK performed similarly on freeze-thaw test.

- Based on the SEM analysis, CCP introduces optimal sized air bubbles in the concrete and fine particles to decrease the number disadvantageous pores.

As conclusion, it can be drawn that $\mathrm{CCP}$ could be advantageous in normal-strength concretes, both from the standpoint of compressive strength and durability.

Acknowledgements Open access funding provided by Budapest University of Technology and Economics (BME). Authors are grateful to the Hungarian Scientific Research Fund (OTKA) for the financial support of the OTKA K 109233 research project. Special thanks to Bengineer House Kft., Duna-Dráva Cement Kft., SIKA Hungária Kft. and MC-Bauchemie Kft. for providing the materials used in the experiments.

Open Access This article is distributed under the terms of the Creative Commons Attribution 4.0 International License (http://creative commons.org/licenses/by/4.0/), which permits unrestricted use, distribution, and reproduction in any medium, provided you give appropriate credit to the original author(s) and the source, provide a link to the Creative Commons license, and indicate if changes were made.

\section{References}

1. Siddique R, Khan MI. Supplementary cementing materials. Berlin: Springer; 2011. https://doi.org/10.1007/978-3-642-178665.

2. Ramezanianpour AM, Hooton RD. A study on hydration, compressive strength, and porosity of Portlandlimestone cement mixes containing SCMs. Cem Concr Compos. 2014;51:1-13.

3. Gruber KA, Ramlochan T, Boddy A, Hooton RD, Thomas MDA. Increasing concrete durability with high-reactivity metakaolin. Cem Concr Compos. 2001;23:479-84.

4. Siddique R, Klaus J. Influence of metakaolin on the properties of mortar and concrete: a review. Appl Clay Sci. 2009;43:392-400.

5. Kubissa W, Simon T, Jaskulski R, Reiterman P, Supera M. Ecological high performance concrete. Proc Eng. 2017;172:595-603.

6. Wilinska I, Pacewska B. Influence of selected activating methods on hydration processes of mixtures containing high and very high amount of fly ash. J Therm Anal Calorim. 2018;133:823-43. https://doi.org/10.1007/s10973-017-6915-y.

7. Özalp F, Yilmaz HD, Kara M, Kaya Ö, Sahin A. Effects of recycled aggregates from construction and demolition wastes on mechanical and permeability properties of paving stone, kerb and concrete pipes. Constr Build Mater. 2016;110:17-23.

8. Aprianti E. A huge number of artificial waste material can be supplementary cementitious material (SCM) for concrete production e a review part II. J Clean Prod. 2017;142:4178-94.

9. Topcu IB, Güncan NF. Using waste concrete as aggreofgate. Cem Concr Res. 1995;25:1385-90.

10. Topcu IB, Sengel S. Properties of concretes produced with waste concrete aggregate. Cem Concr Res. 2004;34:1307-12.

11. Sani D, Moriconi G, Fava G, Corinaldesi V. Leaching and mechanical behaviour of concrete manufactured with recycled aggregates. Waste Manag. 2005;25:177-82.

12. Li J, Zhang C, Xiao J. On statistical characteristics of the compressive strength of recycled aggregate concrete. Struct Concr. 2005;6:149-53. https://doi.org/10.1680/stco.2005.6.4.149.

13. Bignozzi MC, Saccani A. Ceramic waste as aggregate and supplementary cementing material: a combined action to contrast alkali silica reaction (ASR). Cem Concr Compos. 2012;34:1141-8.

14. Puertas F, García-Díaz I, Barba A, Gazulla MF, Palacios M, Gómez MP, Martínez-Ramírez S. Ceramic wastes as alternative raw materials for Portland cement clinker production. Cem Concr Compos. 2008;30:798-805.

15. Mirzahosseini M, Riding KA. Influence of different particle sizes on reactivity of finely ground glass as supplementary cementitious material (SCM). Cem Concr Compos. 2015;56:95-105.

16. Bignozzi MC, Saccani A, Barbieri L, Lancellotti I. Glass waste as supplementary cementing materials: the effects of glass chemical composition. Cem Concr Compos. 2015;55:45-52.

17. Kuzielová E, Žemlička M, Novotný R, Palou MT. Simultaneous effect of silica fume, metakaolin and ground granulated blastfurnace slag on the hydration of multicomponent cementitious binders. J Therm Anal Calorim. 2018. https://doi.org/10.1007/ s10973-018-7813-7.

18. Wu ZB, Guan BH, Lou WB, Ye QQ, Fu HL. Calorimetric study of calcium aluminate cement blended with flue gas desulfurization gypsum. J Therm Anal Calorim. 2009;98(3):737-42. https:// doi.org/10.1007/s10973-009-0107-3.

19. Gruyaert E, Robeyst N, De Belie N. Study of the hydration of Portland cement blended with blast-furnace slag by calorimetry and thermogravimetry. J Therm Anal Calorim. 2010;102(3):941-51. https://doi.org/10.1007/s10973-010-0841-6. 
20. Talero R, Rahhal V. Calorimetric comparison of portland cements containing silica fume and metakaolin. Is silica fume, like metakaolin, characterized by pozzolanic activity that is more specific than generic. J Therm Anal Calorim. 2009;96:383. https://doi.org/10.1007/s10973-008-9096-x.

21. Scheinherrová L, Doleželová M, Havlín J, Trník A. Thermal analysis of ternary gypsum-based binders stored in different environments. J Therm Anal Calorim. 2018;133:177-88. https:// doi.org/10.1007/s10973-018-7398-1.

22. Hoff GC. Porosity-strength considerations for cellular concrete. Cem Concr Res. 1972;2:91-100.

23. Song Y, Li B, Yang E, Liu Y, Ding T. Feasibility study on utilization of municipal solid waste incineration bottom ash as aerating agent for the production of autoclaved aerated concrete. Cem Concr Compos. 2015;56:51-8.

24. Narayanan N, Ramamurthy K. Structure and properties of aerated concrete: a review. Cem Concr Compos. 2000;22:321-9. https:// doi.org/10.1016/S0958-9465(00)00016-0.

25. Fenyvesi O, Jankus B. Opportunities in recycling AAC waste as aggregate for lightweight concrete. Építöanyag J Silic Compos Mater. 2015;67:66-70.

26. Fenyvesi O. Ipari hulladékok újrahasznosítása beton adalékanyagként. In: Meddö? Hulladék? Nem! Haszonanyag! Conference, Budapest, Hungary. 2014; p. 111-8.

27. Borosnyói A. Long term durability performance and mechanical properties of high performance concretes with combined use of supplementary cementing materials. Constr Build Mater. 2016;112:307-24. https://doi.org/10.1016/j.conbuildmat.2016.02. 224.

28. Ženíšek M, Vlach T, Lenka L. Dosage of metakaolin in high performance concrete. Key Eng Mater. 2016;722:311-5. https:// doi.org/10.4028/www.scientific.net/KEM.722.311.

29. MSZ. Testing hardened concrete. EN 12390-7:2009, Part 7: density of hardened concrete, Appendix to Eurocode standard. 2009.
30. Mlinárik L, Kopecskó K, Borosnyói A. Properties of cement mortars in fresh and hardened condition influenced by combined application of SCMs. Építöanyag J Silic Based Compos Mater. 2016;68:62-6. https://doi.org/10.14382/epitoanyag-jsbcm.2016. 11.

31. European Committee for Standardization (CEN). Aggregates for Concrete. EN 12620:2002+A1:2008 European Standard. 2008.

32. European Committee for Standardization (CEN). Testing hardened concrete. Compressive strength of test specimens. EN 12390-3:2009 European Standard. 2009.

33. MSZ. 4715/3-72 standard. Megszilárdult beton vizsgálata. Hidrotechnikai tulajdonságok. (Testing hardened concrete. Hydrotechnical properties. 2010. (in Hungarian).

34. Tikalsky PJ, Pospisil J, MacDonald W. A method for assessment of the freeze-thaw resistance of preformed foam cellular concrete. Cem Concr Res. 2004;34:889-93.

35. European Committee for Standardization (CEN). CEN/TS 12390-9 Testing hardened concrete. Part 9: Freeze-thaw resistance-Scaling. 2010; p. 24.

36. Ibrahim IA, ElSersy HH, Abadir MF. The use of thermal analysis in the approximate determination of the cement content in concrete. J Therm Anal Calorim. 2004;76:713. https://doi.org/10. 1023/B:JTAN.0000032255.58397.4b.

37. Jackson MD, Mulcahy SR, Chen H, Li Y, Li Q, Cappelletti P, Wenk HR. Phillipsite and Al-tobermorite mineral cements produced through low-temperature water-rock reactions in Roman marine concrete. Am Miner. 2017;102(7):1435-50. https://doi. org/10.2138/am-2017-5993CCBY.ISSN0003-004X.

Publisher's Note Springer Nature remains neutral with regard to jurisdictional claims in published maps and institutional affiliations. 